\title{
Diversity in Medical Toxicology: Why This Is Important
}

\author{
Trevonne M. Thompson
}

Published online: 12 July 2013

(C) American College of Medical Toxicology 2013

Medical toxicology is an avant-garde specialty. The care provided by medical toxicologists knows no boundary and encompasses all aspects of the practice of medicine. Medical toxicologists have responded to world disasters, testified before federal regulators regarding medication safety, performed research on novel antidotes, and even alerted authorities to the presence of serial poisoning. Yet in 2013, there is a toxicologic health disparity in the USA. In 2002, the Institute of Medicine released a report entitled Unequal Treatment: Confronting Racial and Ethnic Disparities in Health Care. This report stated that "Evidence of racial and ethnic disparities in healthcare is, with few exceptions, remarkably consistent across a range of illnesses and healthcare services" [1]. The racial and ethnic health and health-care disparity is evident in our field.

Environmental injustice is a term that describes the disproportionately heavy exposure of vulnerable populations to toxic chemicals, contaminated water, unsafe workplaces, and other environmental hazards [2]. The concept of environmental injustice was developed in the 1980s when studies found that waste sites in the Southeastern United States were located in poor counties inhabited, in large part, by AfricanAmericans and Native Americans [2]. Similar waste site distributions were found elsewhere in the USA [2, 3]. Waste sites are not the only sources of environmental injustice, and disproportionate exposure to intoxicants has consequences. African-American children consistently are documented to have higher rates of lead poisoning than white children [4-6]. Air pollution has been linked to increased cancer risk in certain African-American communities [7]. Migrant farm workers have been exposed to work conditions leading to

T. M. Thompson $(\bowtie)$

Department of Emergency Medicine,

Division of Medical Toxicology, University of Illinois at Chicago,

808 S. Wood St. (MC724), Chicago, IL 60612, USA

e-mail: tthomps@uic.edu pesticide toxicity in the fields and, in some cases, exposing their families in the home [8]. These are just a few examples of the many that illustrate the toxicologic health disparity.

Underserved populations, specifically racial and ethnic minorities, suffer disparities in the treatment of cardiovascular diseases, HIV, cancer, and diabetes, among other medical maladies $[1,9]$. The same applies to toxicologic maladies as well. A consistent recommendation to combat racial and ethnic disparities in health care is to increase the proportion of underrepresented US racial and ethnic minorities among health professionals [1]. Within the fold of racial and ethnic minorities, there is the concept of physicians who are underrepresented in medicine. The Association of American Medical Colleges defines underrepresented in medicine as physicians whose numbers in medicine are disproportionally lower than in the US population [10]. This group has historically included African-Americans, Native Americans, Mexican Americans, and mainland Puerto Ricans; however, underrepresented in medicine is not limited to these groups. Racial and ethnic minority physicians are more likely to serve minority and underserved populations and can help health systems improve cultural competence and reduce linguistic barriers $[9,11]$. Racial and ethnic minority patients report higher satisfaction when care is provided by minority health-care professionals [9, 11]. Diversity of faculty and staff in medical education and training has a positive impact on the education of all students $[12,13]$. Racial and ethnic diversity among investigators would broaden the research agenda and increase the likelihood of conducting research within minority communities $[12,13]$. When examining the data regarding diversity in medicine, there is no specific mention of the practice of medical toxicology. While these data apply to our specialty, it is conceivable that the young age of our specialty has precluded specific research by medical toxicologists in this direction.

The 2010 US Census Bureau data show that $13 \%$ of the US population was identified as African-American or Black and 
$16 \%$ were Hispanic [14]. A 2010 report from the AAMC shows that $5 \%$ of emergency physicians, the specialty in which most medical toxicologists are trained primarily, are African-American and 5.3\% are Hispanic [15]. There are no racial and ethnic data available for medical toxicology as a specialty or within our specialty society, the American College of Medical Toxicology.

The strides medical toxicology has made in a short span of time-ACGME recognition for fellowship programs and board certification within the American Board of Medical Specialties, an active and engaged professional societyshow that our field is comprised of energetic and innovative physicians. Within our field, however, increased attention should be given to the concepts of diversity in medicine and toxicologic health disparities and efforts should be made to address their consequences. We should actively recruit physicians of diverse backgrounds into our specialty. We should invite to our meetings and form collaborations with physicians and researchers of various specialties who are working to address issues related to environmental injustice and health disparities. As we are the leaders in all other aspects of medical toxicology, we should become leaders addressing the toxicologic health disparity in all of its facets.

\section{References}

1. Smedley BD, Stith AY, Nelson AR (eds) (2002) Unequal treatment: confronting racial and ethnic disparities in health care. National Academies, Washington, DC

2. Landrigan PJ, Rauh VA, Galvez MP (2010) Environmental justice and the health of children. Mt Sinai J Med 77(2):178-187
3. Norton JM, Wing S, Lipscomb HJ et al (2007) Race, wealth, and solid waste facilities in North Carolina. Environ Health Perspect 115:1344-1350

4. Lane SD, Webster NJ, Levandowski BA et al (2008) Environmental injustice: childhood lead poisoning, teen pregnancy, and tobacco. J Adolesc Health 42:43-49

5. Haley VB, Talbot TO (2004) Geographic analysis of blood lead levels in New York State children born 1994-1997. Environ Health Perspect 112:1577-1582

6. Lamphear BP, Weitzman M, Eberly S (1996) Racial differences in urban children's environmental exposures to lead. Am J Public Health 86:1460-1463

7. Apelberg BJ, Buckley TJ, White RH (2005) Socioeconomic and racial disparities in cancer risk from air toxics in Maryland. Environ Health Perspect 113:693-699

8. Arcury TA, Quandt SA (2003) Pesticides at work and at home: exposure of migrant farmworkers. Lancet 362(9400):2021

9. Heron SL, Lovell EO, Wang E, Bowman SH (2009) Promoting diversity in emergency medicine: summary recommendations from the 2008 council of residency directors (CORD) academic assembly diversity workgroup. Acad Emerg Med $16: 450-453$

10. Association of American Medical Colleges (2013) Underrepresented in medicine definition. https://www.aamc.org/initiatives/urm/. Accessed 19 Apr 2013

11. Peek ME, Kim KE, Johnson JK, Vela MB (2013) "URM candidates are encouraged to apply": a national study to identify effective strategies to enhance racial and ethnic faculty diversity in academic departments of medicine. Acad Med 88:405-412

12. Cohen JJ, Gabriel BA, Terrell C (2002) The case for diversity in health care workforce. Health Aff (Millwood) 21:90-102

13. King TE Jr, Dickinson TA, DuBose TD Jr et al (2004) The case for diversity in academic internal medicine. Am J Med 116:284-289

14. United States Census Bureau (2011) Overview of race and Hispanic origin: 2010. http://www.census.gov/prod/cen2010/briefs/c2010br02.pdf. Accessed 19 Apr 2013

15. Association of American Medical Colleges (2010) Diversity in the physician workforce: facts and figures 2010. http://aamc.org/ factsandfigures. Accessed on 19 Apr 2013 